\title{
The Effect of Syntactic Simplicity and Complexity on the Readability of the Text
}

\author{
Hedayat Eslami \\ Islamic Azad University, Miyandoab, Iran
}

\begin{abstract}
The purpose of this study is to investigate the effect of syntactic simplicity and complexity on the readability of the text. To achieve this, a set of standard reading comprehension passages were syntactically modified to develop three different versions of the same text (i.e., reduced, original, expanded) at different readability levels. A number of 257 senior Iranian EFL students participated in the study. The participants were divided into three proficiency levels of high, mid, and low, each taking the three different versions of the same text. The results revealed that there was no significant difference among the high proficient students' performance on the three versions. However, there were significant differences among the mid and low proficient students' performance on these versions. The results, therefore, indicate that syntactic complexity may create comprehension problems for mid and low proficient students, but not for high proficient ones. The results of this study can be useful for language teachers, syllabus designers and test developers in selecting suitable texts matched to the learners' ability level.
\end{abstract}

Index Terms - readability, syntactic simplicity, syntactic complexity, text accessibility

\section{INTRODUCTION}

Readability or "text difficulty" has been a major area of concern for all those who need to establish the appropriacy of a given text for a pedagogic purpose (Fulcher, 1997). Predicting accurate readability of text is of paramount importance to language practitioners to ensure that the input to which L2 readers are exposed matches their processing ability and provides the basis for the noticing, comprehension and intake of the L2 (Crossley, Greenfield, \& McNamara, 2008).The readers are unlikely to adequately decipher the author's intended meaning if the readability level of texts exceed the readers' ability level (Badgett, 2010). Readability is a complex cognitive phenomenon. "The cognitive load of a text for a reader hinges on the characteristics of a text like lexical choice, syntactic and semantic complexity, discourse level complexity as well as on the background of the user" (Sinha, Sharma, Dasgupta, \& Basu, 2012, p.1142). Reading comprehension, of course, does not merely depend on text variables, but it depends on reader variables as well. However, as the reader variables like background knowledge, motivation, previous reading experience, etc. are beyond the control of the teacher, text variables have received the most attention. (Fulcher , 1997).

\section{REVIEW OF RELATED LITERATURE}

Readability of a text has been defined as the comprehensibility or the ease with which readers are able to read and understand a written text (Oakland \& Lane, 2004; Badgett, 2010). It refers to how well a reader is able to comprehend the content of a particular text through reading. Studies have shown that easy to read texts enhance comprehension, retention, reading speed and reading persistence (Sinha, et al., 2012).In its broader sense, readability refers to the comprehensibility of written text (Homan, Hewit, \& Linder, 1994). Readability describes the combination of structural and lexical difficulty of a text, as well as referring to the amount of new vocabulary and any new grammatical form present. The readability of text is one of the main criteria which should be taken into account when selecting texts to be used in the classroom (Berardo, 2006). Authors and material developers employ a variety of approaches and materials to assist L2 readers by making the texts more comprehensible. One such tool is the use of readability formulas which provide an indication of text readability based on the word and sentence length found in the text (Crossley, Allen, \& McNamara, 2011). There have been, however, many criticisms leveled against these formulas due to their limited scope of data, low reliability, measuring surface-level features (i.e., syntax and vocabulary), and lack of credibility (Oakland \& Lane, 2004) and ignoring comprehension factors (Crossley et al., 2011). Further, these formulas are text-based and do not take into account the reader-based and author-based factors (Kasule, 2011).

An area related to text readability is that of simplification which results in shorter sentences, deletion or rephrasing of complex structure and the use of low-frequency vocabulary in an attempt to increase overall text comprehensibility or make it more readable (Long \& Ross, 1993 cited in O'Donnel, 2009). The purpose of simplified text is to provide L2 readers with texts which are more accessible and more comprehensible (Crossley, et al., 2011). According to Anani Sarab and Karimi (2008), the objective of simplification is to create language which can be better understood by nonnative readers of English texts. Simplification, the most common type of modification, involves decreasing the linguistic complexity of syntactic construction and lexical items (Long, 2007 cited in O'Donneil, 2009). A number of studies (e.g. Crossley \& McNamara, 2008; Leow, 1997; Yano, Long, \& Ross, 1994) have indicated that L2 readers 
better understand simplified texts in comparison with the unmodified versions of the same texts. Leow (1997) argued that simplification of input contributes to the L2 learners' linguistic system by providing more grammatical information, and thus facilitates comprehension in the reading process By the same token, Yano et al. (1994) indicated that simplified texts lead to a better comprehension of texts in comparison to authentic texts. The L2 readers benefit more from simplified text because it provides more comprehensible input and because it is lexically, syntactically, and rhetorically less difficult than authentic texts (Crossley \& McNamara, 2008).

Pedagogically simplified texts, albeit better understood by L2 readers, are not without some undesirable side effects. According to O' Donnel (2009), as a result of simplification, readers are denied access to lexical, linguistic structure and authentic models of language in which linguistic and cultural elements are presented. It may also have a negative impact on language acquisition since it affects linguistic element and content of text. Simplified texts, in fact, deprive learners of opportunities to learn the natural forms of language (Anani Sarab \& Karimi, 2008). These texts also lack the cohesiveness of authentic texts because they are created using readability formulas which cut word and sentence length and delete connectives to shorten the intended texts (Crossley, Louwerse, McCarthy, \& McNamara, 2007).

Syntactic complexity refers to the range of forms that surface in language production and the degree of sophistication of such forms (Ortega, 2003, cited in Lu, 2008). It is one of the major factors which make a text less readable or difficult. An important factor associated with making a text syntactically difficult and more complex is sentence length which is measured in terms of average sentence length in words, number of clauses, letters, and syllables (Agnihorti \& Khanna, 1992). Of course, there are a variety of other factors such as word difficulty and language structure, text structure, discourse style, genre, background knowledge, familiarity with the content, level of reasoning required, format and layout of text, and length of text which interact to influence the complexity of a particular text. (Hess \& Biggam, 2004). In addition, elaboration, coherence and unity, audience appropriateness, quality of the writing and interestingness are other factors which influence text difficulty and accessibility (Graves \& Graves, 2003).

There are a few studies which suggest that complex structures may not hinder comprehension in the reading process. For example, Anderson and Davison (1988) believed that the more complex structures are not necessarily harder to understand if the context contains discourse antecedents for some phrases which the syntax marks as special. Similarly, Crain and Shankweiler (1988) showed that complex structures may not impede comprehension, rather these structures may facilitate comprehension if used in contexts that meet the propositions on their use. Another study conducted about syntactic complexity and its relation to text comprehension revealed that "syntactic simplicity may not be an aid, but a hindrance to comprehension since simplified syntax may decrease explicit textual cohesion" (Carrell, 1987, P. 30).

It follows that investigating the difficulties EFL students encounter in reading process is of great significance. One of the most important factors contributing to students' success in reading process relates to the selection of texts at appropriate difficulty level. Thus, establishing text difficulty is relevant to English teachers and syllabus designers who wish to select appropriate materials for learners at variety of ability levels and other purposes. They also need to know whether pedagogically simplified texts enhance learners' performance in reading. This study, therefore, intends to shed some lights on the effect of syntactic simplicity and complexity on the readability of the text which may facilitate or impede comprehension process by making a text syntactically more readable or less readable. To investigate this problem and achieve the purpose of the study, the following research questions were proposed:

1. Is there any difference in the performance of Iranian high proficient EFL students on different versions of the same text at different readability levels?

2. Is there any difference in the performance of Iranian mid proficient EFL students on different versions of the same text at different readability levels?

3. Is there any difference in the performance of Iranian low proficient EFL students on different versions of the same text at different readability levels?

\section{METHOD}

\section{A. Participants}

A number of 257 EFL students participated in the study. They were all Iranian male and female EFL undergraduate students. All the participants were over the age of 22 and they were senior EFL students. 139 of these participants participated in the pilot study which took place in two stages, 131 participated in the validation process, and the rest of the students served as the sample of the actual study.

\section{B. Instruments}

Two instruments were utilized in the study. The first one was a standard language proficiency test, namely, TOEFL which was used to serve as an indicator of participants' proficiency level and as a criterion to validate the two newlydeveloped tests. The second test was a set of standard reading comprehension texts from which two other versions with different syntactic characteristics were developed resulting in three different sets of reading comprehension passages.

\section{Procedure}

The first step of the study was to develop three syntactically different reading comprehension tests. To accomplish this, a set of standard reading comprehension passages matched to the students' language ability level were selected 
from an original TOEFL. In the next step, these passages were syntactically modified to develop two other versions of these texts. In modifying the texts, a number of syntactic criteria such as readability level, average sentence length, number of sentences, number of relative clauses, types of sentences, etc. were taken into consideration and the texts were modified as follows:

The first version or more readable version (reduced) was developed by splitting up long and complex or compoundcomplex sentences in the original version into short and simple sentences in order to lower the readability levels of the texts. The syntactic characteristics of this version are presented in Table 1.

TABLE 1 .

THE SYNTACTIC CHARACTERISTICS OF THE REDUCED VERSION

\begin{tabular}{|c|c|c|c|c|c|}
\hline \multicolumn{3}{|c|}{ Syntactic Indicator } & passage 1 & Passage 2 & Passage 3 \\
\hline 1 & \multicolumn{2}{|c|}{ Fog Index readability level } & 8.23 & 10.76 & 8.4 \\
\hline 2 & \multicolumn{2}{|c|}{ average sentence length } & 12 & 12.91 & 9.77 \\
\hline 3 & \multicolumn{2}{|c|}{ number of sentences } & 24 & 26 & 31 \\
\hline 4 & \multicolumn{2}{|c|}{ number of words } & 288 & 310 & 303 \\
\hline 5 & \multicolumn{2}{|c|}{ number of relative clauses } & 2 & 3 & 0 \\
\hline 6 & \multicolumn{2}{|c|}{ number of passive verbs } & 5 & 8 & 2 \\
\hline 7 & $\begin{array}{l}\text { types of } \\
\text { sentences: }\end{array}$ & $\begin{array}{l}\text { simple } \\
\text { compound } \\
\text { complex } \\
\text { compound-complex }\end{array}$ & $\begin{array}{l}19 \\
0 \\
4 \\
0\end{array}$ & $\begin{array}{l}1 \\
1 \\
8 \\
0\end{array}$ & $\begin{array}{l}1 \\
1 \\
1 \\
0\end{array}$ \\
\hline
\end{tabular}

The second version (original) was not modified and remained intact. The syntactic characteristics of this version are presented in Table 2 .

TABLE 2.

THE SYNTACTIC CHARACTERISTICS OF THE ORIGINAL VERSION.

\begin{tabular}{|c|c|c|c|c|c|}
\hline \multicolumn{3}{|c|}{ Syntactic Indicator } & passage1 & Passage 2 & Passage 3 \\
\hline 1 & \multicolumn{2}{|c|}{ Fog Index readability level } & 11.69 & 13.81 & 13.01 \\
\hline 2 & \multicolumn{2}{|c|}{ average sentence length } & 18.6 & 23.92 & 20.26 \\
\hline 3 & \multicolumn{2}{|c|}{ number of sentences } & 15 & 24 & 15 \\
\hline 4 & \multicolumn{2}{|c|}{ number of words } & 279 & 305 & 304 \\
\hline 5 & \multicolumn{2}{|c|}{ number of relative clauses } & 5 & 4 & 6 \\
\hline 6 & \multicolumn{2}{|c|}{ number of passive verbs } & 3 & 3 & 4 \\
\hline 7 & $\begin{array}{l}\text { types of } \\
\text { sentences: }\end{array}$ & $\begin{array}{l}\text { simple } \\
\text { compound } \\
\text { complex } \\
\text { compound-complex }\end{array}$ & $\begin{array}{l}5 \\
0 \\
10 \\
0\end{array}$ & $\begin{array}{l}5 \\
1 \\
5 \\
4\end{array}$ & $\begin{array}{l}7 \\
2 \\
4 \\
2\end{array}$ \\
\hline
\end{tabular}

The third version or less readable version (expanded) was developed by combining simple, short and compound sentences in the original version in order to form complex or compound-complex sentences in an attempt to increase the readability levels of the texts. The syntactic characteristics of this version are shown in Table 3 .

TABLE 3.

THE SYNTACTIC CHARACTERISTICS OF THE EXPANDED VERSION.

\begin{tabular}{|l|l|l|l|l|}
\hline \multicolumn{2}{|l|}{ Syntactic Indicator } & Passage 1 & Passage 2 & passage 3 \\
\hline 1 & Fog Index readability level & 19.56 & 19.56 & 16.09 \\
\hline 2 & average sentence length & 37 & 32.1 & 26.76 \\
\hline 3 & number of sentences & 8 & 10 & 12 \\
\hline 4 & number of words & 296 & 321 & 321 \\
\hline 5 & number of relative clauses & 12 & 10 & 10 \\
\hline 6 & number of passive verbs & 6 & 8 & 4 \\
\hline 7 & types of & 1 & 0 & 0 \\
& sentences: & 0 & 2 & 1 \\
& & 5 & 5 & 6 \\
& & comple & 3 & 5 \\
\hline
\end{tabular}

It should be pointed out that vocabulary and content were held constant across the three versions. The texts were modified only syntactically, i.e., the focus was mainly on sentence reduction and sentence expansion.

Pre-testing: The reduced and expanded versions of the tests were pre-tested with two samples of students whose characteristics were similar to those participating in the actual study to ensure that the items have not been affected by syntactic modification of the texts and that no clues have been provided which may help students get the correct answer The results of item analysis performed on these tests revealed that a number of items did not function satisfactorily. The deficient items were identified and modified. Then, the new versions of tests were again pretested with samples of 32 and 38 students, respectively. The item analysis revealed that all the items except two or three functioned satisfactorily. These deficient items were again revised.

Reliability of the tests: The reliability indexes of the reduced and expanded versions, computed using K.R.21 formula of reliability, turned out to be .73 and .76 for reduced and expanded versions respectively. 
Criterion-Related Validity: To establish the validity of the tests, students' scores on these tests were correlated with their scores on the criterion measure (TOEFL) which was administered along with the reduced and expanded versions. A sample of 68 took the reduced versions and 63 took the expanded versions of the texts. The validity of the tests computed using Pearson's Product Moment Correlation Formula turned out to be .71 and .74 for the reduced and expanded versions respectively. The reliability and validity of the tests are shown in Table 4.

TABLE 4.

THE RELIABILITY AND VALIDITY OF THE READING TESTS

\begin{tabular}{|l|l|l|}
\hline Variable & reduced & expanded \\
\hline reliability: r (KR-21) & .73 & .76 \\
\hline validity: r xy & .71 & .74 \\
\hline
\end{tabular}

In the next step, these three different versions were administered to a sample of approximately 257 subjects. 88 of these participants took the reduced form, 91 took expanded form, and 78 took original form. In addition to these three versions of the same texts, students in each group took the language proficiency test (i.e., TOEFL). Therefore, each student had two scores: One on the TOEFL, and the other on one of the three different versions.

To achieve the purpose of the study and answer the research question, the subjects had to be divided into three homogeneous proficiency levels of low, mid, and high. To this end, the Standard Deviation and the Mean of the students' scores on TOEFL were computed. The results are shown in Table 5.

TABLE 5.

DESCRIPTIVE STATISTICS FOR TOEFL.

\begin{tabular}{|l|l|l|l|}
\hline Variable & $\mathrm{N}$ & $\mathrm{SD}$ & $\mathrm{X}$ \\
\hline reduced & 88 & 15.42 & 50.7 \\
\hline original & 78 & 14.82 & 50.11 \\
\hline expanded & 91 & 16.08 & 49.15 \\
\hline
\end{tabular}

The participants in each group were divided into three proficiency levels by taking SD and of each group, i.e., the participants whose TOEFL scores were between half SD above and half SD below mean ( $\pm 1 / 2$ SD) were taken as mid proficient group, those obtaining scores above $\quad+1 / 2 \mathrm{SD}$ as high proficient, and those obtaining scores below - 1/2 SD as low proficient group. The number of participants at each level and their mean scores on each version are presented in Tables 6, 7 and 8 .

TABLE 6.

THE HIGH PROFICIENT LEVEL

\begin{tabular}{|l|l|l|l|l|}
\hline \multicolumn{5}{|c|}{ THE HIGH PROFICIENT LEVEL } \\
\hline \multirow{2}{*}{$\bar{\Xi}$} & High proficient & version & $\mathrm{N}$ & \\
\cline { 3 - 5 } & reduced & 27 & 11.48 \\
\cline { 3 - 5 } & original & 24 & 12.04 \\
\cline { 3 - 5 } & & expanded & 29 & 10.75 \\
\hline
\end{tabular}

TABLE 7.

THE MID PROFICIENT LEVEL

\begin{tabular}{|c|c|c|c|c|}
\hline & & version & $\mathrm{N}$ & \\
\hline \multirow{3}{*}{$\begin{array}{l}\vec{D} \\
\stackrel{d}{\lrcorner}\end{array}$} & \multirow[t]{3}{*}{ Mid proficient } & reduced & 36 & 9.88 \\
\hline & & original & 34 & 10.23 \\
\hline & & expanded & 36 & 8.94 \\
\hline
\end{tabular}

TABLE 8.

THE LOW PROFICIENT LEVEL

\begin{tabular}{|c|c|c|c|c|}
\hline & & version & $\mathrm{N}$ & \\
\hline \multirow{3}{*}{$\begin{array}{l}\overline{0} \\
\text { נ] } \\
\end{array}$} & \multirow[t]{3}{*}{ Low proficient } & reduced & 25 & 7.12 \\
\hline & & original & 21 & 7.04 \\
\hline & & expanded & 26 & 5.38 \\
\hline
\end{tabular}

In order to ensure the homogeneity of the subjects at each proficiency level, three separate one-way ANOVA were carried out as follows:

TABLE 9.

ONE-WAY ANOVA FOR HOMOGENEITY OF HIGH PROFICIENT LEVEL.

\begin{tabular}{|l|l|l|l|l|l|}
\hline Source of Variation & D.F & SS & MS & F & Fcrit \\
\hline Between Groups & 2 & 124.7448 & 62.3724 & 1.3436 & 3.11 \\
\hline Within Groups & 77 & 3574.4552 & 46.4215 & & \\
\hline Total & 79 & 3699.2000 & & & \\
\hline
\end{tabular}


TABLE 10.

ONE-WAY ANOVA FOR HOMOGENEITY OF MID PROFICIENT LEVEL.

\begin{tabular}{|l|l|l|l|l|l|}
\hline Source of variation & D.F & SS & MS & F & Fcrit \\
\hline Between Groups & 2 & 69.3011 & 34.6505 & 1.5413 & 3.09 \\
\hline Within Groups & 103 & 2315.6046 & 22.4816 & & \\
\hline Total & 105 & 2384.9057 & & & \\
\hline
\end{tabular}

TABLE 11.

ONE-WAY ANOVA FOR HOMOGENEITY OF LOW PROFICIENT LEVEL

\begin{tabular}{|l|l|l|l|l|l|}
\hline Source of Variation & D.F & SS & MS & F & Fcrit \\
\hline Between Groups & 2 & 107.4929 & 53.7464 & .6741 & 3.13 \\
\hline Within Groups & 69 & 5501.6182 & 79.7336 & & \\
\hline Total & 71 & 5609.1111 & & & \\
\hline
\end{tabular}

The above Tables reveal that in all the three levels, the $\mathrm{F}$ ratio did not equal or exceed the $\mathrm{F}$ critical value implying that there are no significant differences among the participants at each proficiency level and that they are homogeneous in terms of language proficiency.

\section{RESULTS}

In order to come up with reasonable answers to the research questions, the students' performance on the three different versions of the same texts at each proficiency level had to be compared. Therefore, three separate One-Way ANOVA were run in order to determine whether there were significant differences among the three groups (i.e., reduced, original, expanded) at each proficiency level. These analyses are discussed below.

To answer the first research question, a One-Way ANOVA was carried out to compare the performance of the high proficient students on the reduced, original, and expanded versions. The results of this analysis are shown in Table 12.

TABLE 12.

ONE-WAY ANOVA FOR SDRCT BY HIGH PROFICIENT LEVEL.

\begin{tabular}{|l|l|l|l|l|l|}
\hline Source of Variation & D.F & SS & MS & F & F crit \\
\hline Between Groups & 2 & 26.3325 & 13.1663 & 2.2647 & 3.11 \\
\hline Within Groups & 77 & 447.6550 & 5.8137 & & \\
\hline Total & 79 & 473.9875 & & & \\
\hline
\end{tabular}

Table 12 shows that the $\mathrm{F}$ ratio did not exceed the $\mathrm{F}$ critical implying that there is no significant difference among the high proficient students on the reduced, original and expanded versions of the tests. Therefore, the first null hypothesis could not be rejected because the high proficient students' did not perform significantly differently on the three versions of the same texts.

To answer the second research question, another One-Way ANOVA was carried out in order to compare the performance of mid proficient students on the three versions of the tests. The results of this analysis are presented in Table 13.

TABLE 13.

ONE-WAY ANOVA FOR SDRCT BY MID PROFICIENT LEVEL.

\begin{tabular}{|l|l|l|l|l|l|}
\hline Source of Variation & D.F & SS & MS & F & F crit \\
\hline Between Groups & 2 & 31.5322 & 15.7661 & 5.0189 & 3.09 \\
\hline Within Groups & 103 & 323.5621 & 3.1414 & & \\
\hline Total & 105 & 355.0943 & & & \\
\hline
\end{tabular}

As the Table shows the $\mathrm{F}$ ratio exceeded the $\mathrm{F}$ critical value implying that there are significant differences among mid proficient students' performance on the reduced, original, expanded versions. Therefore, the second null hypothesis is safely rejected. A post-hoc analysis, Scheffe test, was conducted to find out where the differences lay. The results of this analysis are presented in Table 14.

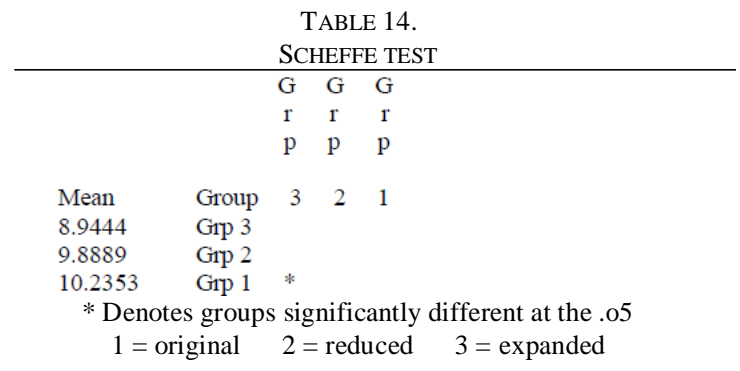

The Table shows that the mid proficient students in the original group performed significantly differently from those in the reduced and expanded groups. 
To answer the third research question, another One-Way ANOVA was run in order to compare the low proficient students' performance on the three tests. The results presented in Table 15 reveal that $\mathrm{F}$ ratio exceeded the $\mathrm{F}$ critical value implying that the three groups performed significantly differently from one another. Therefore, the thirds null hypothesis is also safely rejected.

TABLE 15 .

ONE-WAY ANOVA BY LOW PROFICIENT LEVEL

\begin{tabular}{|l|l|l|l|l|l|}
\hline Source of Variation & D.F & SS & MS & F & Fcrit \\
\hline Between Groups & 2 & 48.1982 & 24.0991 & 12.8161 & 3.13 \\
\hline Within Groups & 69 & 129.7462 & 1.8804 & & \\
\hline Total & 71 & 177.9444 & & & \\
\hline
\end{tabular}

A Scheffe Test was conducted to find out the location of differences among the three groups. The results of this analysis are presented in Table 16.

\begin{tabular}{|c|c|c|c|c|c|}
\hline \multicolumn{6}{|c|}{$\begin{array}{c}\text { TABLE } 16 . \\
\text { SCHEFFE TEST }\end{array}$} \\
\hline & & $\mathrm{G}$ & G & $\mathrm{G}$ & \\
\hline & & $r$ & $r$ & $\mathrm{r}$ & \\
\hline & & $\mathrm{p}$ & $\mathrm{p}$ & $\mathrm{p}$ & \\
\hline Mean & Group & 3 & 2 & 1 & \\
\hline 5.3846 & \multicolumn{5}{|l|}{ Grp 3} \\
\hline 7.0476 & Grp 2 & \multicolumn{4}{|l|}{ * } \\
\hline 7.1200 & Grp 1 & \multicolumn{4}{|l|}{ * } \\
\hline \multicolumn{6}{|c|}{ * Denotes groups significantly different at the .05} \\
\hline \multicolumn{2}{|c|}{$1=$ original } & & $=\mathrm{re}$ & duced & $3=$ expanded \\
\hline
\end{tabular}

The Table indicates that the reduced and original groups performed significantly differently from the expanded group.

\section{DISCUSSION}

The purpose of the study was to investigate whether different versions of the same text at different readability levels produced any significant differences among the EFL students' performance in reading comprehension tests. The results of the study revealed that there were no significant differences among the high proficient students' performance on the three different versions of the same texts. This means that these students performed similarly better on the three syntactically modified texts. Therefore, pedagogically modified texts were not effective in ameliorating high proficient learners' comprehension and, in fact, these students could benefit from textual cohesion and complex grammatical relations within the text to decipher the author's intended meaning. However, with regard to mid and low proficient, the results indicated that the students' performance on the original and reduced versions of the texts was significantly different from their performance on the expanded version. This means that unlike the high proficient level, the students at the mid and low levels performed better on the original and simplified versions which were considered to be more readable than the expanded one. Thus, syntactic modification in the form of shortening sentences and lowering the readability level of text promote elementary and intermediate level readers' comprehension of reading material. These results are in line with a recent study conducted by Baleghizadeh and Borzabadi (2007 cited in Anani Sarab \& Karimi, 2008) who found that linguistic modifications were more helpful for low proficient learners and that the high proficient learners did not benefit from text simplification. Therefore, simplified texts could be conducive in L2 instruction for lower and mid proficient learners. The results of this study are in contrast to those which suggested that syntactic complexity was not a hindrance to readers' comprehension in the reading process (e.g., Agnihorti \& Khanna, 1992).

\section{PedAgOGICAL IMPLiCATiOnS}

The results of this study will provide language teachers with useful information as to the difficulty level of the materials to be presented to learners at different proficiency levels. For example, the language teachers will take into account the types of texts (i.e., authentic vs. simplified) to use in the classroom and will definitely use authentic text for pedagogic purposes at advanced levels without any linguistic simplifications. However, for mid and low proficient learners, they may need to modify the texts to match them to the learners' ability level. The EFL language teachers and language testers will also be able to consider the difficulty level of a single-sentence test items by ascertaining their readability levels using special readability formulas. Syllabus designers will also be able to select appropriate materials at a variety of ability levels to be included in the students' text books.

\section{REFERENCES}

[1] Agnihorti, R.K., \& Khanna, A.L. (1992). Evaluating the readability of school text books: An Indian study. Journal of Reading $35,282-288$.

[2] Alderson, C. \& Urqhart, H. (1984). Introduction: What is reading? In C. Alderson \& A.H. Urqhart (eds.), Reading in a Foreign Language. London: Longman, 15-28. 
[3] Anderson, R.C., \& Davison, A. (1988). Conceptual and empirical bases of readability formulas. In A. Davison \& G.M. Green (eds.), Linguistic complexity and text comprehension: Readability issues reconsidered. Hillsdale, NJ: Erlbaum, 23-54.

[4] Badgett, B.A. (2010). Toward the development of a model to estimate the readability of credentialing-examination materials. UNLV, Paper 185

[5] Berardo, S. A. (2006). The use of authentic materials in the teaching of reading. The Reading Matrix 6.2, 60-68.

[6] Carrell, P.L. (1987). Readability in ESL. Reading in a Foreign Language 4, 21-40.

[7] Crain, S., \& Shankweiler, D. (1988). Syntactic complexity and reading acquisition. In A. Davison \& G.M. Green (eds.), Linguistic complexity and text comprehension: Readability issues reconsidered. Hillsdale, NJ: Erlbaum, 23-54.

[8] Crossley, S.A., Louwerse, M.M., McCarthy, P.M., \& McNamara, D. (2007). A linguistic analysis of simplified and authentic texts. The modern Language Journal, 91, 15-30.

[9] Crossley, S.A., Greenfield, J., \& McNamara, D.S. (2008). Assessing text readability using cognitively based indices. TESOL Quarterly 42.3, 475-493.

[10] Crossley, S.A., \& McNamara, D.S. (2008). Assessing L2 reading text at the intermediate level: An approximate replication of Crossley, Louwerse, McCarthy, \& Mcnamara (2007). Language Teaching 41.3, 409-429.

[11] Crossley, S.A., Allen, D.B., \& McNamara, D.S. (2011). Text readability and intuitive simplification: A comparison of readability formulas. Reading in a Foreign Language 23.1, 84-101.

[12] Graves, M.F., \& Graves, B.B. (2003). Scaffolding reading experiences: Designs for student success (2 ${ }^{\text {nd }}$ Ed.) ChristopherGordon.

[13] Fulcher, G. (1997). Text difficulty and accessibility: Reading formulae and expert judgment. System 4, 404-519.

[14] Hess, K. \& Biggam, S. (2004). A discussion of increasing text complexity. Appendices for New England Common Assessment Program (NECAP).

[15] Homan, S., Hewitt, M., Linder, S. (1994). The development and validation of a formulae for measuring single-sentence test item readability. Journal of Educational Measurement 31, 349-358.

[16] Lu, X. (2008). Automatic measurement of syntactic complexity using the revised developmental level scale. American Association for Artificial Intelligence.

[17] Kasule, D. (2011). Textbook readability and ESL learners. Reading and Writing, 2.1, 63-76.

[18] Klare , G. (1985). Matching reading materials to readers: The role of readability estimate in conjunction with other information about comprehensibility. In H. Theodore, \& E.J. Cooper (eds.), Reading, thinking, and concept development. New York: College Entrance Examination Board, 233-256.

[19] Oakland, T. \& Lane, H. (2004). Language, reading, and readability formulas: Implications for developing and adapting tests. International Journal of Testing 4, 239-252.

[20] O'Donnel, M.E. (2009). Finding middle ground in second language reading: Pedagogic modifications that increase Comprehensibility and vocabulary acquisition while preserving authentic text features. The Modern Language Journal, 93.4, 512-533.

[21] Sinha, M., Sharma, S., Dasgupta, T., \& Basu, A. (2012). New readability measure for Bangla and Hindi texts. Proceedings of COLING, Mumbai.

[22] Schulz, R. (1981). Literature and readability: Bridging the gap in foreign language reading. Modern Language Journal 65, 4353.

[23] Urqhart, A.H. (1984). The effect of rhetorical ordering on readability. In A. Anderson and A.H. Urqhart (eds.), Reading in a foreign language, Longman: London, 161-1280.

[24] Yano, Y., Long, M., \& Ross, S. (1994). Effects of simplified and elaborated texts on foreign language reading comprehension. Language learning, 44.2, 189-219.

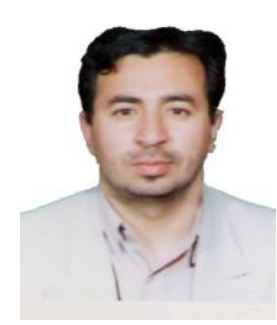

Hedayat Eslami was born in Malekan, East Azarbijan Province, Iran in 1973. He received his B.A degree in TEFL from Islamic Azad University, Maragheh branch, Iran in 1996. He got his M.A degree in TEFL from Iran University of Science and Technology in 1999 and now he is a Ph.D student in TEFL in Islamic Azad University, Tabriz branch. He is a faculty member of Islamic Azad University, Miyandoab branch. He has been teaching English for more than 14 years in several universities. His major area of interest is language teaching, language testing, linguistics, and ESP. 